\title{
Detection of Extended Spectrum $\beta$ Lactamase and Amp C $\beta$ Lactamase Resistance in the Gram Negative Bacterial Isolates of Ventilator Associated Pneumonia
}

\author{
David Agatha and B. Subitha*
}

Department of Microbiology, ThanjavurMedical College, Thanjavur, India

*Corresponding author

\begin{tabular}{|l|}
\hline Ke y w or d s \\
$\beta$ Lactamase, Gram \\
negative bacteria, \\
Ventilator, \\
Pneumonia \\
\hline Article Info \\
\hline $\begin{array}{l}\text { Accepted: } \\
\text { 10 January } 2019 \\
\text { Available Online: } \\
\text { 10 February } 2019\end{array}$ \\
\hline
\end{tabular}

\section{Keywords}

$\beta$ Lactamase, Gram Ventilator,

Article Info

Accepted:

Available Online

10 February 2019

\section{A B S T R A C T}

Ventilator-associated pneumonia (VAP) is an important nosocomial infection in mechanically ventilated patients at intensive care unit (ICU). The administration of accurate and timely initial empirical antibiotic therapy is essential to reduce the morbidity and mortality from Ventilator-associated pneumonia. Initial empiric antimicrobial therapy for VAP greatly depends on the type of causative pathogen and its resistance pattern. During the six months study period, 196 patients received mechanical ventilation. Endo tracheal aspirates were collected from 22 mechanically ventilated patients with suspected ventilator associated pneumonia. 19 organisms were isolated. All Cefoxitin resistant isolates were studied for the presence of plasmid mediated AmpC beta-lactamase enzyme by Inhibitor disk based method and inducible AmpC beta-lactamase production by Ceftazidime-imipenem antagonism test (CIAT).ESBL production in the gram negative isolates was detected by Phenotypic Confirmatory Test. Incidence rate of VAP was 9.7\%. Klebsiella pneumoniae (26\%) was the most common organism followed by Pseudomonas aeruginosa (21\%) and Acinetobacter spp (16\%). (53\%) of Gram negative isolates were positive for ESBL production. (6\%) was positive for plasmid mediated Amp C beta lactamase production and $(6 \%)$ was positive for inducible Amp C beta lactamase production. Due to the increasing incidence of drug-resistant organisms, VAP requires an early diagnosis and appropriate antibiotic treatment, to prevent mortality and morbidity. Hence, knowing the bacterial isolates and their antibiotic resistance pattern is essential to improve the clinical outcome of VAP.

\section{Introduction}

Ventilator associated pneumonia is the most common nosocomial infection in patients receiving mechanical ventilation, It occurs in $9-27 \%$ of mechanically ventilated patients (Arindam Dey et al., 2007, Gupta et al., 2011). Ventilator associated pneumonia (VAP) is a hospital acquired pneumonia that occurs 48 hours or more after tracheal intubation. It is classified as early onset or late onset pneumonia (Hanan H et al., 2014, Xiaofang Cai et al., 2011). Early onset pneumonia occurs within four days of intubation and late onset pneumonia develops after five days. In general, early VAP is caused by pathogens that are sensitive to antibiotics, whereas late onset VAP is caused by drug resistant 
pathogens such as various beta-lactamases (AmpC $\beta$ lactamase (AmpC), extended spectrum $\beta$-lactamases (ESBL) and metallo- $\beta$ lactamases $(\mathrm{MBL})$ producing gram negative isolates and methicillin-resistant Staphylococcus. aureus (MRSA)'(Marcos et al., 2013, Ramakrishna et al., 2012).

The most common mechanism of resistance in Gram negative bacteria is by the production of $\beta$ lactamases which inactivate $\beta$ lactam antibiotics. Among the $B$ lactamases, Extended Spectrum $B$ lactamases (ESBL) and Amp C B-lactamases are most commonly produced. Organisms producing ESBL are resistant to all penicillins, first, second and third generation cephalosporins and monobactam, however remain sensitive to carbapenems and cephamycins. AmpC betalactamases have broad substrate specificity and are classified as class $\mathrm{C}$ according to Ambler and group 1 by Bush-JacobyMedeiros. These enzymes are both chromosomal and plasmid mediated and confers resistance to narrow, broad spectrum cephalosporins, and B lactam B lactamase inhibitor combinations (Varsha Gupta et al., 2007; Gupta et al., 2013)

Initial empiric antimicrobial therapy for VAP greatly depends on the type of causative pathogen and its resistance pattern. Increasing drug resistance rates among the pathogens that frequently cause VAP may compromise treatment and result in prolongation of hospital stay and increase in mortality. There is a wide geographic and temporal variability of antibiotic resistance among the bacterial isolates of VAP (Chittawatanarat et al., 2014, Jean-Louis Trouillet et al., 1998). Hence this prospective study was conducted to evaluate the bacteriological profile, antibiotic resistance pattern, ESBL and AmpC $\beta$ lactamase (AmpC) production in gram negative isolates of ventilator associated pneumonia.

\section{Materials and Methods}

This prospective study was conducted in a Tertiary care hospital over a period of 6 months. In that period 196 ventilated patients were observed. Endotracheal aspirates were collected from the patients on mechanical ventilation for more than 48 hours with new or progressive infiltrates, consolidation or cavitation on chest X-ray and one of the following: (a) New onset purulent bronchial secretions with leukopenia (white blood cell $<1500 / \mathrm{mm} 3)$ or leukocytosis $(\geq 12,000 / \mathrm{mm} 3)$, or core temperature $\geq 38.5$ or $\leq 36^{\circ} \mathrm{C}$ without other cause.

The endotracheal aspirates were sent to the lab and processed immediately. The samples were first subjected to Gram's staining and then quantitative cultures were performed.

Samples were mechanically liquefied and homogenized by vortexing for $1 \mathrm{~min}$. Then $0.01 \mathrm{~mL}$ of sample solution was inoculated on sheep blood agar, chocolate agar (CA), and MacConkey agar by using $4 \mathrm{~mm}$ Nichrome wire loop. All plates were incubated overnight at $37^{\circ} \mathrm{C}$ and $\mathrm{CA}$ plates at $37^{\circ} \mathrm{C}$ in candle jar. All plates were checked for growth after 24 and $48 \mathrm{hrs}$ of incubation. A detailed biochemical tests were performed to identify the significant growth of organism, and antibiotic sensitivity testing were performed on Mueller-Hinton agar plates by KirbyBauer disc diffusion method. Zone diameter was measured and interpreted as per the Clinical and Laboratory Standards Institute (CLSI) guidelines

Gram negative isolates resistant to 3rd Generation Cephalosporins were tested for ESBL production.

Phenotypic detection of ESBL production in the gram negative isolates by Phenotypic Confirmatory Test. 
Ceftazidime $(30 \mu \mathrm{g})$ disk and a Ceftazidime plus Clavulanic acid (Ca $30 \mu \mathrm{g}+\mathrm{Caz} 10 \mu \mathrm{g}$ ) disks were placed at a distance of $20 \mathrm{~mm}$ apart on a lawn of culture of the suspected ESBL producing clinical isolates on MHA.

The plates were incubated at $37^{\circ} \mathrm{C}$ overnight. The test organism was considered to produce ESBL if the zone size around the Ceftazidime plus Clavulanic acid disk increased $>5 \mathrm{~mm}$ in comparison to the third generation Ceftazidime disk alone.

All Cefoxitin resistant Gram negative isolates were tested for AmpC beta-lactamase enzyme production.

Detection of plasmid mediated AmpC betalactamase production by Inhibitor disk based method.

The test culture was swabbed on MuellerHinton agar plates. Cefoxitin $(30 \mu \mathrm{g}))$ disk and Cefoxitin /BoronicAcid (BA)disk were placed at a distance of $20 \mathrm{~mm}$ from center to center.

An increase of $>.5 \mathrm{~mm}$ around Cefoxitin /BA compared to Cefoxitin alone was considered positive for the presence of AmpC production (Philip et al., 2005).

Detection of inducible AmpC beta-lactamase production by Ceftazidime-imipenem antagonism test (CIAT)

The test culture was swabbed on MuellerHinton agar plates. Imipenem disk $(10 \mu \mathrm{g})$ and Cefoxitin disk were placed $20 \mathrm{~mm}$ apart (edge-to-edge) from a Ceftazidime disk (30 $\mu \mathrm{g}$. Antagonism was indicated by a visible reduction in the inhibition zone around the Ceftazidime disk adjacent to the Imipenem or Cefoxitin disks. This was regarded as positive for inducible AmpC beta-lactamase production (Vlademir et al., 2007).

\section{Results and Discussion}

During the study period, a total of 196 patients were on mechanical ventilation at Intensive Medical Care Unit, Neonatal Intensive Care Unit and Pediatric Intensive Care Unit in a Tertiary care Hospital. Endo tracheal aspirates were collected from 22 mechanically ventilated patients with suspected ventilator associated pneumonia. 19 organisms were isolated and 3 Endo tracheal aspirates were reported as no growth. Incidence rate was $9.7 \%$. Klebsiella pneumoniae (26\%) was the most common organism followed by Pseudomonas aeruginosa (21\%), Acinetobacter spp (16\%), Staphylococcus aureus (16\%), Klebsiella oxytoca (11\%), Citrobacter spp (5\%) and Streptococcus sp (5\%).

The antibiotic susceptibility testing for Gram positive organisms revealed $100 \%$ sensitivity to Vancomycin and all the three Staphylococcus aureus isolates were resistant to cefoxitin (Fig. 1 and 2).

Gram negative organisms except Klebsiella pneumoniae and Acinetobacter spp were $100 \%$ sensitive to Imipenem.

Gram negative isolates $(n=11)$ resistant to $3 \mathrm{rd}$ Generation Cephalosporinswere tested for ESBL production. 4 Klebsiella pneumoniae isolates, 2 Klebsiella oxytoca isolates, 1 Acinetobacter spp isolate and 1 Pseudomonas aeuriginosa were positive for ESBL production

Two Klebsiella pneumoniae, two Acinetobacter spp one Pseudomonas aeruginosa resistant to Cefoxitin were tested for Amp C $\beta$ lactamase production. One Acinetobacter spp was positive for plasmid mediated Amp C beta lactamase production. One Pseudomonas aeruginosa was positive for inducible Amp C beta lactamase 
production. Out of 15 gram negative isolates, $8(53 \%)$ were positive for ESBL production, 1 $(6 \%)$ was positive for plasmid mediated Amp
$\mathrm{C}$ beta lactamase production and $1(6 \%)$ was positive for inducible Amp C beta lactamase production (Table 1).

Table.1 Antibiotic sensitivity pattern of Gram negative organisms isolated from ventilator associated pneumonia

\begin{tabular}{|l|c|c|c|c|c|}
\hline Drugs & $\begin{array}{c}\text { Klebsiella } \\
\text { pneumoniae }\end{array}$ & $\begin{array}{c}\text { Klebsiella } \\
\text { oxytoca }\end{array}$ & $\begin{array}{c}\text { Pseudo monas } \\
\text { aeruginosa }\end{array}$ & $\begin{array}{c}\text { Acineto } \\
\text { bacter spp }\end{array}$ & $\begin{array}{c}\text { Citrobacter } \\
\text { spp }\end{array}$ \\
\hline Amikacin & 80 & 50 & 50 & 67 & 100 \\
\hline Gentamycin & 40 & 50 & 50 & 33 & 100 \\
\hline Ciprofloxacin & 20 & 0 & 75 & 0 & 100 \\
\hline Ceftazidime & 20 & 0 & 50 & 33 & 100 \\
\hline Piperazilin tazobactum & 80 & 100 & 75 & 33 & 100 \\
\hline Imipenem & 80 & 100 & 100 & 33 & 100 \\
\hline Cefoxitin & 60 & 100 & 75 & 33 & 100 \\
\hline
\end{tabular}

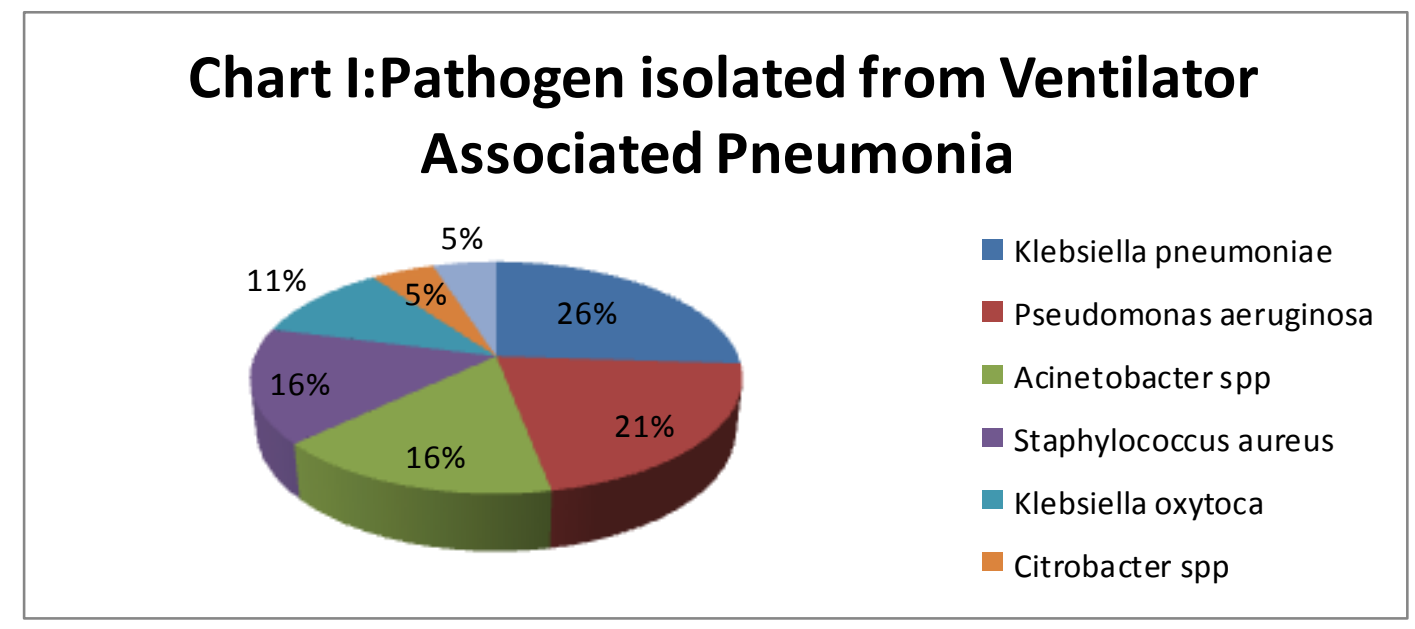

Fig.1 Inducible Amp C beta lactamase detection by Ceftazidime-imipenem antagonism test

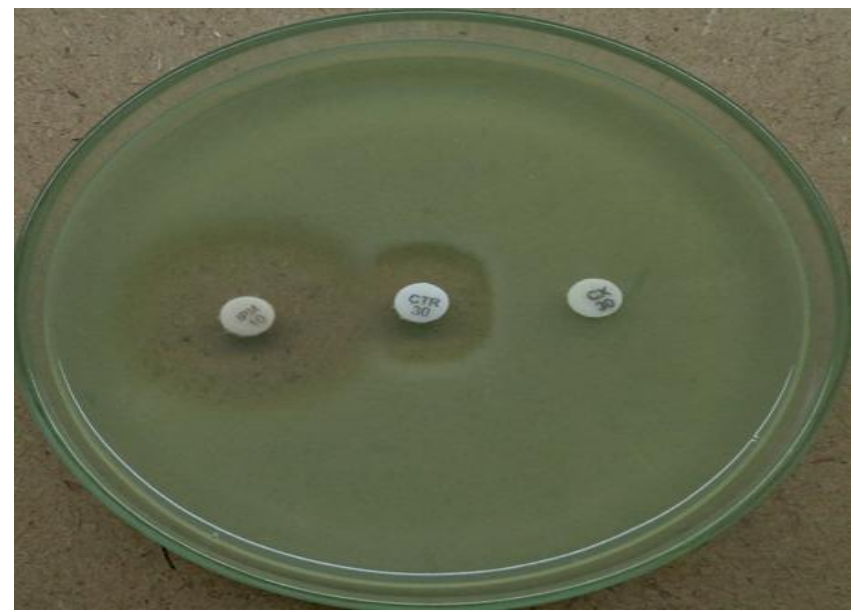


Fig.2 Plasmid mediated Amp C beta lactamase detection by Inhibitor disk based method

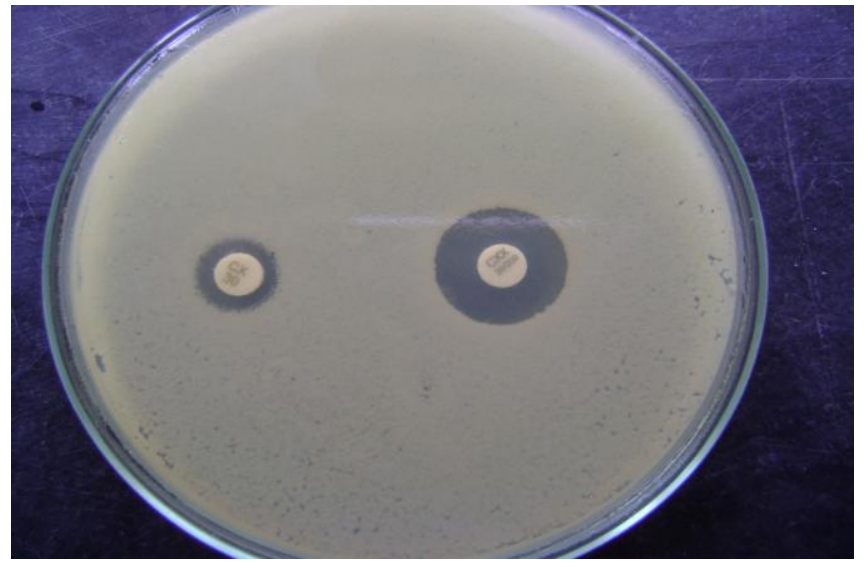

VAP requires a rapid diagnosis and initiation of appropriate antibiotic treatment, to prevent mortality and morbidity. Inappropriate and inadequate antibiotic treatment causes emergence of drug resistance in pathogens and poor prognosis in patients (Steven et al., 2006, Ali Amanati et al., 2017, Su Young Chi et al., 2012)

The incidence of VAP in our study was $9.7 \%$, which was lower than studies done by Alok Gupta et al., (28.04\%), SarojGolia et al., (35.78\%), Gadani et al., (37\%) and Dey et al., (45.4\%) Rajashekaran et al., reported a very high incidence rate of $73 \%$.The lower incidence rate may be due to death of most of the patients on the day of mechanical ventilation itself.

Out of 19 VAP cases, $43 \%$ were categorized under early-onset VAP and 57\% under lateonset VAP which was in concordance with study conducted by Dey et al., Klebsiella pneumoniae and Pseudomonas aeruginosa were the commonest isolates obtained in both early and late onset VAP cases, which were also reported as the commonest isolates by study conducted by Ramakrishna et al., (2012).

In our study $53 \%$ of Gram negative isolates were ESBL producers. Saroj Golia et al., and
Dey et al., also observed a high prevalence of ESBL producers in their study. Chromosomal Amp C $\beta$ Lactamase resistance was seen in $6 \%$ of our isolates and plasmid mediated Amp $\mathrm{C}$ beta lactamase production was seen in $(6 \%)$ which was similar to Gupta et al., observation (11\%). Cefoxitin resistance in non-Amp C producing Klebsiella pneumoniae is often due to porin deficient mutants. The interruption of a porin gene by insertion sequences is a common type of mutation that causes the loss of porin expression and increased Cefoxitin resistance in Klebsiella pneumoniae.

Our results suggest no difference in the rate of drug resistant pathogens between early-onset and late-onset VAP. Many studies have shown a higher association between resistant pathogens and late-onset VAP. This association is due to previous antibiotic therapy, time on mechanical ventilation, and local factors, which are institution specific. Ibrahim and colleagues have reported resistant pathogens to be common in both early-onset and late-onset. The overall picture suggests that number of drug-resistant strains of various organisms is rising and is an important cause of VAP in our setting.

In conclusion, this study suggests that most cases of VAP in our setting are caused by highly resistant strains. Local epidemiological 
data like this should be collected at all centers, as such information can help in guiding the initial empirical antibiotic therapy, which would be more rationale and help in decreasing mortality and morbidity. This would also help in preventing development of more resistant strains.

\section{References}

Ali Amanati, Abdollah Karimi, Alireza Fahimzad, Ahmad Reza Shamshiri. Incidence of Ventilator-Associated Pneumonia in Critically Ill Children Undergoing Mechanical Ventilation in Pediatric Intensive Care Unit Children (Basel). 2017 Jul; 4(7): 56.

ArindamDey and Indira Bairy, Incidence of multidrug-resistant organisms causing ventilator-associated pneumonia in a tertiary care hospital: A nine months' prospective study, Ann Thorac Med. 2007 Apr-Jun; 2(2): 52-57.

Chittawatanarat K1, Jaipakdee W. Microbiology, resistance patterns, and risk factors of mortality in ventilatorassociated bacterial pneumonia in a Northern Thai tertiary-care university based general surgical intensive care unit. Am J RespirCrit Infect Drug Resist. 2014 Aug 16;7:203-10.

Gupta A, Agrawal A, Mehrotra S, Singh A, Malik S, Khanna A. Incidence, risk stratification, antibiogram of pathogens isolated and clinical outcome of ventilator associated pneumonia. Indian J Crit Care Med. 2011; 15: 96-101.

Hanan H. Balkhy, Aiman El-Saed, RanaMaghraby, HDrug-resistant ventilator associated pneumonia in a tertiary care hospital in Saudi Arabia Ann Thorac Med. 2014 Apr-Jun; 9(2): 104-111

Jean-Louis Trouillet, Jean Chastre, Ventilator-associated Pneumonia
Caused by Potentially Drug-resistant Bacteria. All AJRCCM Issues>Vol. 157, No. 2 | Feb 01, 1998.

Marcos I Restrepo, MD MSc, Janet Peterson, Comparison of the Bacterial Etiology of Early-Onset and Late-Onset Ventilator-Associated Pneumonia in Subjects Enrolled in 2 Large Clinical Studies. Respir Care. 2013 Jul; 58(7): 1220-1225.

Mukhopadhyay C, Bhargava A, Ayyagari A. Role of mechanical ventilation and development of multidrug resistant organisms in hospital acquired pneumonia. Indian J Med Res. 2003; 118: 229-35.

Philip E. Coudron, Inhibitor-Based Methods for Detection of Plasmid-Mediated AmpC $\beta$-Lactamases in Klebsiella spp., Escherichia coli, and Proteus mirabilis. J ClinMicrobiol. 2005 Aug; 43(8): 4163-4167.

Ramakrishna PaiJakribettu and Rekha Boloor, Characterisation of aerobic bacteria isolated from endotracheal aspirate in adult patients suspected ventilator associated pneumonia in a tertiary care center in Mangalore. Saudi J Anaesth. 2012 Apr-Jun; 6(2): 115-119.,

Saroj Golia,1 Sangeeth, K.T. Microbial Profile of Early and Late Onset Ventilator Associated Pneumonia in The Intensive Care Unit of A Tertiary Care Hospital in Bangalore, India $\mathbf{J}$ Clin Diagn Res. 2013 Nov; 7(11): 2462-2466.

Steven M. Koenig and Jonathon D. Truwit Ventilator-Associated Pneumonia: Diagnosis, Treatment, and Prevention Clin Microbiol Rev. 2006 Oct; 19(4): 637-657.,

Su Young Chi, M.D., Tae Ok Kim, M.D., Chan Woo Park, M.D., Jin Yeong Yu, M.D., Boram Lee, M.D., Ho Sung Lee, M.D., Yu Il Kim, M.D., Sung Chul Lim, M.D., Bacterial Pathogens 
of Ventilator Associated Pneumonia in a Tertiary Referral Hospital. Tuberc Respir Dis (Seoul). 2012 Jul; 73(1): 32-37.

Gupta, V., R. Garg, S. Garg, J. Chander, Coexistence of Extended Spectrum Beta-Lactamases, AmpC BetaLactamases and Metallo-BetaLactamases in Acinetobacter baumannii from burns patients: a report from a tertiary care centre of India Ann Burns Fire Disasters. 2013 Dec 31; 26(4): 189-192

Varsha Gupta An update on newer $\beta$ lactamases Indian J Med Res 126, November 2007, pp 417-427
Vlademir Vicente Cantarelli, Everton Inamine. Utility of the CeftazidimeImipenem Antagonism Test (CIAT) to Detect and Confirm the Presence of Inducible AmpC Beta-Lactamases Among Enterobacteriaceae. The Brazilian Journal of Infectious Diseases 2007; 11(2): 237-239

Xiao-fang Cai, Ji-min Sun, Lian-sheng Bao, and Wen-bin $\mathrm{Li}$, Distribution and antibiotic resistance of pathogens isolated from ventilator-associated pneumonia patients in pediatric intensive care unit. World $\mathrm{J}$ Emerg Med. 2011; 2(2): 117-121

\section{How to cite this article:}

David Agatha and Subitha, B. 2019. Detection of Extended Spectrum $\beta$ Lactamase and Amp C $\beta$ Lactamase Resistance in the Gram Negative Bacterial Isolates of Ventilator Associated Pneumonia. Int.J.Curr.Microbiol.App.Sci. 8(02): 1139-1145.

doi: https://doi.org/10.20546/ijcmas.2019.802.132 